artigo

[ EMANUELA MORA ]

É professora de Sociologia de Produtos Culturais na Faculdade de Ciências Políticas da Università Cattolica del Sacro Cuore em Milão. É membro do Conselho Diretivo do Centro de Estudos da Moda e da Produção Cultural da mesma universidade e da Comissão Científica do Consórcio Interuniversitário Milano Fashion Institute. É responsável pela disciplina Moda no curso Master de Comunicação para a Indústria Cultural da Università Cattolica. Suas pesquisas direcionam-se especialmente aos campos da indústria cultural, juventude, moda e costumes.

E-mail: emanuela.mora@unicatt.it

\title{
Perspectivas da moda sustentável na Itália'
}

\section{Perspectives of sustainable fashion in Italy}

[resumo] Neste artigo, vamos mostrar como as peculiaridades da moda na Itália, que Ihe permitiram afirmar-se no mundo de forma autônoma e original em comparação com outros sistemas nacionais, representaram nos últimos anos um fator de relativa fragilidade, se cruzadas com alguns efeitos do processo de globalização. Ao mesmo tempo, contudo, elas conferem à moda italiana um DNA que, valorizado na perspectiva da sustentabilidade, pode significar a matriz de um novo renascimento.

[abstract] In this article we intend to show how the peculiarities of fashion in Italy, which allowed the country to establish itself in the world, autonomous and original, in comparison with other national systems, represented, in the last few years, a factor of relative fragility, if crossed with some effects of the process of globalization. At the same time, however, they offer Italian fashion a DNA which, valued under the perspective of sustainability, may represent the matrix of a new rebirth.

[keywords] italian fashion; clothing; textile; sustainability. 


\section{Introdução}

0 fenômeno da moda na Itália consiste em um sistema de produção e consumo que tem suas raizes em diferentes tradições regionais - a alta-costura romana; a alfaiataria masculina de Nápoles, Abruzzo e Roma; as butiques de moda e a intuição de comercialização internacional de Florença; o prêt-à-porter de Milão; as tradições manufatureiras provinciais que foram gradualmente transformadas em um complexo e peculiar sistema de indústria cultural - e representou para a Itália contemporânea, do pós-guerra em diante, um motor econômico e tecnológico, bem como um depósito de imaginário e dispositivos simbólicos para a modernização. Em particular, parece possivel identificar três âmbitos específicos em que a moda desempenharia tal papel. Primeiro, ela contribuiu para o processo de rápida industrialização que atingiu o pais nas duas décadas que se seguiram à Segunda Guerra Mundial, permitindo-lhe recuperar em grande parte a distância que o separava das outras grandes nações europeias. Em segundo lugar, promoveu a modernização dos estilos de vida para uma população que, num curto espaço de tempo, deslocou o centro de gravidade de sua vida e experiência do campo para as cidades. Por último, pouco a pouco nas décadas seguintes, os processos de modernização já maduros em niveis europeu e mundial encontravam obstáculos e novos desafios; o sistema de moda italiano, juntamente com alguns outros setores estratégicos da economia nacional, descobriu ter em si os genes adequados para experimentar novos modelos organizacionais para uma produção de excelência que combina manufatura e conteúdos intangiveis, excelência industrial e tradição cultural, características sintetizadas na etiqueta Made in Italy. Durante as últimas décadas do século XX e nesta primeira parte do século XXI, no entanto, esse processo de modernização se mostrou concluído, consumado, em certo sentido, sem que fossem elaboradas estratégias de inovação, capazes de permitir ao país a conservação da posição de liderança internacional incontestada. Devido a um conjunto complexo de fatores que não poderá ser analisado aqui, os desafios que a globalização trouxe ao sistema de moda italiano requerem uma mudança de ritmo e um estalo criativo para iniciar eficazes processos inovadores.

\section{Peculiaridades e fragilidades da moda italiana}

Quando falamos de moda, hoje, referimo-nos geralmente a um fenômeno cujas raizes remontam a meados do século XIX, quando Charles Frederick Worth, costureiro inglês, erradicado em Paris, abre seu ateliê e revoluciona o relacionamento com a clientela, oferecendo em intervalos sazonais um caderno de desenhos e modelos criados por ele, inaugurando desse modo a figura do estilista, artista e mestre que assina as suas criações e veste a aristocracia e a alta burguesia europeia, e não apenas francesa (DE MARLY, 1990; GNOLI, 2012). Mas concentrarmos nossa atenção sobre a Itália, a moda no sentido moderno, aqui referido, de fato remonta a um século mais tarde, em meados do século XX, quando se completa o ciclo iniciado por Worth e definido por alguns estudiosos como a "moda dos cem anos" (LIPOVETSKY, 1989). A entrada da Itália no sistema mundial da moda, na verdade, é reconstruída a partir do fim da Segunda Guerra Mundial, apoiada e alimentada por um forte relacionamento com os Estados Unidos da América, que, no abalado país do mediterrâneo, vislumbraram um parceiro produtivo e promissor para atender às necessidades de seus consumidores da classe média, cada vez mais exigentes em termos de conteúdos estilisticos, mas restritos a uma capacidade de gasto insuficiente para cobrir os custos das criações francesas, ainda consideradas como a excelência da moda.

Nesse início, que deve muito aos Estados Unidos, do ponto de vista técnico, econômico e comercial, bem como cultural, temos em sintese todas as caracteristicas relevantes do sistema de moda italiano. A partir desses anos e graças aos recursos injetados no país, como em outros paises que aderiram ao "Programa de Recuperação Europeia", por meio do famoso Plano Marshall, na Itália se constitui um sistema difundido nas regiões de pequenas e médias empresas, ainda artesanais, mas em processo de industrialização. A integração de base geográfica e mercadológica, que dá vida ao peculiar sistema da indústria provincial, ocorre por meio da recuperação e atualização de antigas tradições artesanais, que contribuem para a introdução de tecnologia e maquinários de produção importados dos Estados Unidos (PARIS, 2006). 0 encontro entre as habilidades artesanais e o potencial inovador oferecido 
por máquinas desenvolvidas ad hoc para diferentes trabalhos será uma oportunidade para o início de outro segmento do sistema, das máquinas têxteis, o que é um elemento importante para a integridade da cadeia de produção, outra característica original do sistema de moda italiano. Num nível técnico, uma importante contribuição adicional para o desenvolvimento de um sistema industrial da moda foi fornecida pela assim chamada "revolução do tamanho" (GFT, 1986; MERLO, 2003a), também apoiada pela experiência norte-americana no setor têxtil do vestuário. No início dos anos 1950, o GFT (Gruppo Finanziario Tessile), uma empresa fundada em Turim, em 1930, a partir da fusão de duas das mais antigas empresas do setor, havia organizado uma verdadeira e própria pesquisa antropométrica, medindo uma amostra da população (cerca de 25 mil pessoas) em todo o território nacional (GFT, 1986). Como apontado por Merlo (2003a, p. 684-686), esse instrumento de padronização, usado nos Estados Unidos para produzir em larga escala um vestuário ready to wear, de simples e ordinária fatura, induz uma profunda transformação na confecção italiana, e abre o caminho para a criação do prêt-à-porter, marca distintiva da moda italiana no cenário internacional: "Em vez de dar um impulso à padronização da produção, aumentou drasticamente a diferenciação dos modelos" que podem ser produzidos sobre bases industrial ou semi-industrial, criando assim as condições para que fosse possivel incorporar nos modelos a serem desenvolvidos industrialmente um elevado conteúdo estilístico e criativo.

Por último, não se pode esquecer que o mercado interno dos anos após o fim da Segunda Guerra Mundial não foi capaz de absorver a crescente produção de vestuário de qualidade, para a qual, então, o mercado americano representou uma saída viável, bem como a confirmação precoce de uma vocação internacional que enquanto eleva imediatamente o nível da concorrência, constitui também um estímulo contínuo à experimentação e implementação de processos de produção inovadores.

0 primeiro ponto que precisa ser posto em relevo a fim de compreender no que consiste o sistema de moda italiano é, portanto, o papel fundamental de modernização que a indústria têxtil e do vestuário tem desempenhado na reconstrução do pós-guerra, e que para a Itália significou também o verdadeiro início de um processo de industrialização generalizada. Como se sabe, tal industrialização teve um caráter regional e sub-regional (BECATINI, 2000; MAGGIONI; NOSVELLI, 2003) com o desenvolvimento de numerosas províncias, não só no campo dos têxteis e vestuário, embora neste setor, particularmente pleno em mercadorias. A concentração geográfica de muitas empresas operantes no mesmo segmento acelerou o processo de industrialização de um país que se movia de uma situação de grande atraso, se comparado com os outros grandes países europeus. Em particular, foram fatores de modernização a presença de conhecimento tácito em contínua evolução e compartilhado nas províncias, as economias temporais e de escala possibilitadas pela proximidade territorial entre atores econômicos interdependentes e a presença de empresas que operam em todas as etapas da cadeia produtiva, numa ótica que muitas vezes antecipou, sem contudo explicitar estratégias organizacionais, a lógica pós-fordista da empresa generalizada.

0 segundo ponto a ser destacado refere-se às culturas do consumo; o desenvolvimento de uma indústria da moda contribui de modo significativo para a modernização do consumo na Itália. A partir dos anos 1950, e ao longo das décadas seguintes, tão logo a industrialização começou a dar os seus frutos, criando um bem-estar cada vez mais difundido com a progressiva expansão das classes médias também na Itália, a moda, juntamente com outras expressões da indústria cultural, como o cinema e a televisão, desempenha uma função adicional modernizadora: ela contribui para a modernização do imaginário (GIACCARDI, 2004), sugerindo novas estéticas, novos modos de fazer, artigos de vestuário para novas ocasiões de uso surgidas nos cenários 
urbanos de trabalho e de lazer, contextos e posições sociais para muitas pessoas novas em relação aos lugares e aos hábitos de vida antes da guerra (MORINI, 2005). Trata-se de um processo de modernização cultural de uma característica particular, orientado para a criação de padrões de avaliação e de gosto dominantes e correspondentes aos hábitos que a burguesia tinha herdado a partir de valores caros à aristocracia, padrões capazes de incluir por meio do consumo o maior número possível de camadas da população (MORA, 2009a, 2009b). As culturas modernas do consumo italiano, portanto, desenvolvem-se de acordo com os modelos que podemos definir como top-down, com um importante papel desempenhado pelas agências culturais (mídia, publicidade, as próprias empresas) e um protagonismo popular menos pronunciado em comparação a outros países, como o Reino Unido e/ou a Alemanha, onde as modas de rua desenvolveram-se de forma independente na segunda metade do século $X X$, influenciando fortemente 0 sistema de produção. Os efeitos de tal modernização não são sentidos uniformemente por toda a península italiana à medida que estes efeitos acompanham, em primeiro lugar, as grandes cidades do norte, onde nas décadas após a Segunda Grande Guerra concentra-se também a migração interna das regiões meridionais e do campo. É nestes grandes centros que a moda, fenômeno urbano por definição (SIMMEL, 1996; BENJAMIN, 1986), tanto no passado como no presente (BREWARD; GILBERT, 2006), representa um recurso particularmente significativo para a modernização do imaginário (ROCAMORA, 2009).

A relação entre moda e cidade, na Itália, no entanto, também se apresenta com uma roupagem diferente, relacionada às formas de distribuição. Na Itália, com efeito, o modelo histórico típico de ponto de venda é constituído pela loja especializada multimarca, a butique, que também está ligada a uma vertente particular da produção de vestuário com elevado conteúdo cultural. Nos numerosos centros urbanos de muitas regiões italianas, com uma vocação artística e turística pronunciada, a moda encontra um palco cênico significativo no qual as butiques multimarcas se integram com os pontos de venda monomarcas das grandes marcas de luxo. Assim, é alimentado um processo já em vigor a partir do imediato pós-guerra, em que moda, arte e turismo se promovem reciprocamente, colocando assim a marca italiana em uma posição privilegiada e específica do imaginário internacional (STEELE, 2003). Em seguida, o processo foi desencadeado pela combinação entre Hollywood e Cinecittà, sistema de infraestrutura para o cinema amplamente utilizado por diretores e produtores norte-americanos, os quais rodaram na Itália numerosos filmes em que a paisagem e as cidades da península apareciam com todo o seu fascínio (MALOSSI, 1998, 1999). Nas décadas seguintes, esse processo foi impulsionado pelo desenvolvimento do turismo de arte e de lazer e reforçado pelo crescente papel desempenhado pela indústria da moda, que, presente muitas vezes nos centros de arte e cultura preferidos pelos turistas, põe em vitrina o melhor de uma produção de excelência concentrada nas províncias mais próximas (SANTAGATA, 2007). E isso representa o terceiro aspecto da modernização a que fizemos referência. Uma modernização peculiar que nas décadas de ouro da moda italiana se concretizou na etiqueta Made in Italy, como uma síntese do "bonito e bem feito", expressão que se tornou a principal mensagem da Câmara Nacional de Moda Italiana, a saber, a associação que reúne as principais grifes italianas e coordena as atividades institucionais, especialmente a organização de desfiles de moda. Mais recentemente, essa etiqueta tornou-se objeto de uma reconceituação, com o objetivo de reafirmar a eficácia de um modelo de negócio aparentemente em declínio em relação às formas de concentração internacional e de padronização de processos industriais.

Ao longo das décadas, como dissemos, tal processo alcançou a plena maturidade e está agora em perigo de reproduzir-se de um modo meramente conservador, sem dar novo impulso à inovação do sistema. Em particular, podemos identificar cinco elementos que se revelam particularmente críticos.

1. A moda contemporânea tem gradualmente incorporado e absorvido uma ampla variedade de referências formais e estéticas, seguindo um modelo de acumulação: saias longas e curtas, calças largas e cigarretes, trajes habituais e "descombinados", jaquetas e calças etc. Como no campo da arte, também na moda, para criar algo novo, atualmente, capaz de representar uma verdadeira e própria inovação estética, é muito difícil: tudo já foi visto alguma vez em algum lugar. Algo está mudando no campo da arte, sobretudo graças ao uso das novas tecnologias digitais, e esse tipo de 
pesquisa está interessando cada vez mais também na moda. De qualquer modo, a introdução de novas dimensões estéticas no campo da moda aplica-se apenas a alguns artistas-designers, cujas criações não são definitivamente muito comercializáveis no mercado do vestuário e se adequariam melhor ao mercado de arte.

2. 0 processo de branding envolve hoje não apenas os segmentos do mercado de luxo, mas também muitos segmentos ao longo de toda a pirâmide, até o mercado de massa. A grife, que já foi o marco industrial que garantia a criatividade do designer em sua competição com os mestres da alta-costura, perdeu toda a conotação de singularidade artística e foi substituída pelo brand: uma imagem-signo que combina significados arbitrários e valores atribuídos a um objeto que, de um ponto de vista material, muitas vezes é indistinguível daqueles produzidos pelos concorrentes.

3. A competição entre os mercados nacionais que tradicionalmente têm sido líderes em moda e os novos investidores, como China, Brasil, Índia, é atualmente muito elevada e, de um ponto de vista econômico (por exemplo, os custos trabalhistas), dificilmente sustentável para os primeiros.

4. A contratação de marcas afirmadas mundialmente não pode ser realisticamente combatida. As razões para isso são muitas e tem a ver com os diferentes interesses dos atores envolvidos. 0 problema principal e mais complexo são os custos. De um lado, os produtos falsificados são produzidos em países onde os custos laborais são muito baixos, pois os direitos dos trabalhadores são frequentemente violados e as empresas não são obrigadas a seguir as leis restringentes em matéria de proteção ambiental ou segurança. De outro lado, o conteúdo específico dos produtos de moda autênticos não é muito diferente dos produtos contrafeitos - a única diferença (aquela que determina a grande diferença no preço dos produtos para o consumidor final), de fato, é muitas vezes a etiqueta que os fakes utilizam ilegalmente. Além disso, não podemos ignorar que para algumas marcas a presença de itens falsificados representa uma confirmação de seu próprio valor (se a marca é copiada significa que é verdadeiramente importante), e não, ao contrário, uma verdadeira perda econômica, devido à falta de vendas (a maioria das pessoas que compram artigos de moda falsificados está perfeitamente ciente disso e não compraria um original, porque é muito caro). $E_{\text {, por }}$ último, o consumidor que adquire produtos falsificados e mercadorias contrafeitas, muitas vezes segue estratégias racionais e não se sente de forma alguma enganado: essas mercadorias constituem apenas uma das muitas variantes que enchem o seu guarda-roupa e que emprega em suas práticas de autorrepresentação.

5. Atualmente, é generalizada uma crescente insatisfação por parte dos consumidores em relação à opacidade do sistema econômico e financeiro global, juntamente com a consciência de que grande parte das informações que circulam não é, na verdade, manipulada por indivíduos únicos. Tal insatisfação cria uma necessidade social de transparência em questões que dizem respeito à cadeia produtiva e à distribuição de poder nela. Essa solicitação hoje é ouvida apenas em determinados nichos de públicos e atores econômicos, mas cresce um discurso público sobre essas questões e um novo setor econômico do fair trade e de responsabilidade corporativa está se afirmando também na indústria da moda.

Por meio da recuperação de antigos saberes artesanais, da relação com o território e a cultura que ele expressa, e também da pesquisa de novos processos de produção e estilos organizacionais, muitas empresas italianas que operam no setor têxtil-vestuário e da moda estão à procura da ressignificação dos valores que tradicionalmente sustentaram o Made in Italy, em uma versão original da economia sustentável.

\section{A moda sustentável na Itália}

A partir do final do século $X X$, o chamado desafio da sustentabilidade é considerado internacionalmente uma das mais inovadoras fronteiras do luxo, e, portanto, 
particularmente estimulante para a indústria da moda, ainda que assimilado com atraso em relação a outros setores produtivos, em especial, o agroalimentar, o energético e o do design, que há muito tempo assumiram como foco de suas funções de pesquisa e desenvolvimento as questões relacionadas à sustentabilidade, especialmente ambiental, de produtos e processos de produção. A adoção de estratégias sustentáveis é apresentada às empresas dos sistemas de moda mais avançados como uma possivel resposta a dois processos complexos que têm questionado os equilíbrios que se consolidaram no curso do século XX. 0 primeiro está relacionado às consequências da globalização e como isso afetou os sistemas de moda; o segundo se refere à evolução do modelo de consumo, por sua vez influenciado pela forma com que o sistema de produção se desenvolveu nas últimas décadas.

Nesse período, a moda industrial tem aproveitado as oportunidades que a globalização dos mercados trouxe e assim fez amplo uso da deslocalização da produção para reduzir os custos dos segmentos no início da cadeia e nas estratégias de extensão da marca, especialmente nos setores merceológicos contíguos dos acessórios, da casa, do acolhimento turístico. Dessa forma, as empresas mais sólidas mantiveram amplas margens para investir na imagem desmaterializada, encarnada pelo brand e posta como valor por um acentuado processo de financeirização (PAMBIANCO; TESTONI, 2008). Outra face do processo de globalização, como mencionado anteriormente, consistiu na afirmação de um grande número de marcas localizado em todos os níveis da pirâmide do mercado, dos segmentos mais elevados de luxo, onde se posicionam as marcas históricas da moda moderna, tais como Armani, Valentino, Gucci, aqueles considerados mercado de massa, em que se encontram atualmente algumas das marcas mais populares, como Zara, H\&M, Oviesse. 0 principal resultado desses processos pode ser considerado um efeito de democratização: produtos de marca com os brands mais exclusivos estão agora acessiveis para atingir públicos cada vez maiores - e hoje residentes principalmente em paises fora da Europa, nas economias emergentes mais agressivas. Ao mesmo tempo, os itens de vestuário e acessórios que incorporam as últimas tendências da estação estão nas coleções das marcas que operam também em níveis mais baixos do mercado, permitindo a experiência da moda até mesmo para aqueles que não poderiam adquirir as marcas mais exclusivas. Tais resultados, no entanto, trouxeram consigo alguns efeitos colaterais que explicam o interesse pela questão da sustentabilidade também no campo da moda. Em particular, a consolidação em nível global de um sistema industrial do têxtil e vestuário, com a renovação das coleções em ritmo cada vez mais acelerado, contribuiu significativamente para a exploração dos recursos ambientais, em especial, pelo elevado consumo de água e energia requerido pela produção têxtil, e por meio da poluição do solo e dos cursos de água provocada pelos fertilizantes e aditivos químicos utilizados na prática de cultivo intensivo, principalmente nas plantações de algodão. Além disso, a deslocalização da produção em países com baixos custos trabalhistas levou à exploração do trabalho manual de operários que recebem salários insuficientes e sem qualquer proteção social e sindical (PERNA, 1998; ROSS, 2004). Finalmente, a abundante oferta de marcas e de publicidades que são apresentadas como valores e estilos de vida desejáveis produz uma espécie de saturação do imaginário, no qual não há mais espaço para qualquer novo significado associável aos produtos de moda, todos já propostos e pré-interpretados pelas sofisticadas campanhas de comunicação de todas as marcas, na busca desesperada de características originais que lhes permitam diferenciar-se dos concorrentes (MORA, 2013).

Para o sistema da moda italiano, fundado sobre um tecido produtivo difuso e concentrado em base provincial, esse conjunto de fatores produziu efeitos significativos. Em primeiro lugar, a deslocalização trouxe consigo efeitos de ruptura da forte solidariedade e interdependência entre as empresas pertencentes às mesmas províncias e a crise dos comerciantes mais frágeis da cadeia territorial, substituídos por concorrentes mais vantajosos nos países de deslocalização (FINTONI, 2008; TATARA; CORÒ; VOLPE, 2006). Perante a crescente crise de um modelo econômico que, apesar de suas fragilidades, ainda é a espinha dorsal do sistema econômico italiano, as instituições de governança das províncias industriais perceberam recentemente que uma das maneiras de reconstruir a solidariedade e as interações no interior do tecido industrial italiano é a requalificação cultural das províncias, como "containers evocativos" 
dos valores da modernidade que giram em torno do desenvolvimento sustentável, do bem-estar das pessoas e da qualidade dos produtos (OSSERVATORIO NAZIONALE DISTRETTI ITALIANI, 2013). Na mesma direção, vale destacar os debates e ações que, durante a primeira década do século XXI, incluíram a redefinição e regulamentação da etiqueta Made In Italy (BUCCl; CODELUPPI; FERRARESI, 2011). Os temas em torno dos quais se concentrou o debate e que encontraram eco na lei de 2010 assumem que o caminho para a indústria têxtil e da moda italiana está na valorização das origens territoriais, que estão ligadas às características culturais e históricas da excelência manufatureira, e no respeito das normas europeias em matéria de proteção do trabalho, do meio ambiente e da saúde dos consumidores. Segue-se, portanto, que, pelo menos no âmbito legislativo, as questões relativas à sustentabilidade dos processos de produção na indústria têxtil e do vestuário estão estritamente ligadas às vinculadas ao reconhecimento do caráter insubstituivel da origem territorial como marca de garantia e de qualidade.

Nesse contexto, também na Itália, os modelos de consumo mudaram profundamente. Enquanto as fases de crescimento e afirmação internacional da moda italiana, entre os anos 1960 e início dos anos 1990, ocorreram juntamente com uma grande expansão do consumo em geral, e os de vestuário em particular, a partir da segunda metade da década de 1990, o consumo de moda abrandou-se e mostrou dinâmicas críticas e abaixo da média dos consumos em geral (RICCHETTI, 2011). Do ponto de vista qualitativo, a falta de crescimento no consumo de vestuário está associada a uma mudança na postura dos consumidores, que se tornaram mais seletivos em suas compras, atentos ao conteúdo do produto e ao serviço pós-venda fornecido pelas marcas adquiridas. Os consumidores têm desenvolvido tal comportamento como uma estratégia de adaptação à saturação do imaginário causada pela proliferação de marcas (BUCCl, 1995), que, com suas campanhas publicitárias, oferecem imagens correspondentes ao seu posicionamento no mercado e às estéticas que compõem 0 mundo de referência para os seus consumidores ideais. Como em muitas outras áreas, particularmente no caso da moda, de fato, as campanhas publicitárias funcionam como toda obra de criação, construindo assim mundos possíveis, nos quais o público pode descobrir constelações de significados que evocam potenciais experiências (SEMPRINI, 1993). Os mundos propostos, porém, apesar de muito numerosos, não são infinitos, uma vez que finitos são os valores que regem a moda, como a beleza, elegância, novidade, juventude, luxo, esportividade (BARTHES, 2006); e finitos são os esquemas visuais (as relações cromáticas, de simetria/assimetria, o ritmo das figuras, os gestos etc.) por meio dos quais eles podem ser representados nas mais sofisticadas campanhas publicitárias (CERIANI, 1995). 0 resultado é um efeito de alienação e falta de interesse por parte do público que nos anos 1990 participou mais ativamente desses processos de comunicação, e que já não é mais seduzido por imagens repetitivas que aludem a mundos demasiadamente frequentados no imaginário.

Segundo Ricchetti (2011), o modelo de consumo que se consolida nesse contexto é uma versão aparentemente paradoxal de um esquema definido como trading up/trading down por Silverstein e Fiske (2004). De acordo com esse esquema, os consumidores da classe média estão dispostos a adquirir bens de uma faixa de preço mais elevada que o habitual (trading up), quando estes Ihe parecem particularmente envolventes no plano emocional. Esses produtos devem ter valores estéticos elevados, mas também performances funcionais e conteúdo material superior aqueles garantidos pelos produtos costumeiramente adquiridos. Para aqueles dos quais não é esperado desempenho funcional elevado e envolvimento emocional, bens classificáveis como triviais, os consumidores estão se voltando para produtos de preços básicos (trading down). Um grupo crescente de consumidores parece estar se orientando para a prática do trading up, voltando-se para produtos que incorporam os valores da sustentabilidade ambiental e social, sob forma de benefícios técnicos e de conteúdo material 
coerente com esses valores. 0 conteúdo estético inspirado na tendência da estação e incorporado em produtos do mercado fast-fashion é considerado, em vez disso, um requisito trivial do vestuário, enquanto continua a ser o principal motor da escolha de compra comum e repetida. Para esses itens, então, o consumidor pratica o trading down, sem esperar destes qualquer benefício particular, senão aquele de invocar a tendência da estação (RICCHETTI, 2011).

Os estudos e as pesquisas que nos últimos dez anos têm tentado interpretar esses fenômenos trazem à luz, agora mais do que nunca, como a lógica linear de uma cadeia de produção que, em modo progressivo e uniforme, veicula conteúdos projetuais, materiais e manufaturados, representações da mídia, partindo dos departamentos técnicos das empresas, por meio da cadeia de distribuição até o consumidor final, não é mais um modelo de referência eficiente (RUGGERONE, 2001; HETHORN; ULASEWICZ, 2008). Em vez disso, propõe-se um modelo de rede no qual são considerados potencialmente centrais os stakeholders, ou seja, as diversas partes interessadas, dos fornecedores aos empregados, acionistas, consumidores, instituições governamentais etc. (GUENZA, 2011). Considerá-los centrais significa acreditar que cada um deles possa iniciar um processo de produção, de distribuição, de comunicação, de consumo que seja capaz de interpelar os sujeitos que constituem os outros nós da rede como interlocutores que visam um objetivo comum.

A estrutura de cluster (PORTER, 2000) geograficamente localizada no sistema italiano parece trazer em si o potencial para reconstituir a solidariedade da cadeia, embora em uma lógica não mais linear, e reativar as relações entre os stakeholders, incluindo os consumidores e instituições governamentais locais. Os primeiros têm interesse no bem-estar e na satisfação pessoal, os segundos, em salvaguardar o ambiente comum e a qualidade do trabalho como um recurso coletivo para o tecido social. Isso mostra claramente a ligação entre uma economia geograficamente localizada, como a italiana, e a agenda cultural da sustentabilidade.

Essa relação encontra expressão concreta em algumas das exigências das cadeias de produção, incluindo "utilizar os recursos locais, garantir a ocupação e o know-how dos territórios, incorporar aos produtos elementos distintivos das culturas e das tradições locais como elemento intangível (...)", e ainda, "desenvolver a criatividade e as habilidades individuais e aproximar os cidadãos das decisões sobre o seu futuro" (MARACCHI, 2011, p. 138). Algumas empresas e associações empreendedoras, como 0 Centro de Florença para a Moda Italiana e a Câmara Nacional de Moda Italiana, foram mais longe, promovendo pesquisas, simpósios e guias sobre modelos estratégicos para desenvolver tal relação.

Em todos os casos, torna-se explícita a necessidade de combinar as exigências de sustentabilidade emergentes em nível dos processos de produção e distribuição, e as expressas pelos consumidores, que também parecem preocupados com a confiabilidade das informações prestadas pelas empresas e órgãos de certificação (JUCKER, 2011).

As estratégias com as quais as empresas e instituições enfrentam essa necessidade podem ser atribuidas a duas grandes familias, apenas analiticamente distinguiveis, aquelas que se baseiam na inovação tecnológica e aquelas que partem de uma imposição projetual que considera o design um fator de promoção de mudança social. Inovação e mudança podem partir de qualquer das diversas fases da cadeia: o cultivo e extração das fibras têxteis, o ciclo de vida do produto, os seus usos, a eliminação. De acordo com algumas interpretações, uma concentração excessiva no papel das inovações tecnológicas pode desviar a atenção do fato de que a opção por uma indústria têxtil-vestuária sustentável é fruto de uma progressiva assunção de responsabilidade de todos os atores envolvidos no sistema como partes interessadas (WELTERS, 2008). Uma abordagem que começa por considerar, por outro lado, o design como um recurso que permite criar coleções - e os processos para realizá-las como uma resposta às necessidades de sustentabilidade emergentes de diferentes partes da cadeia -, parece mais adequada para explicar a sustentabilidade como um conteúdo cultural estratégico (MAGNI, 2008; FLETCHER, 2008).

Conforme afirmamos, porém, é quase somente de um ponto de vista analítico ser possível distinguir o foco na inovação tecnológica daquele do design. No design, com efeito, entrelaçam-se dois tipos de processos: de um lado, uma atenção à dimensão estética dos produtos e aos significados históricos e culturais 
que incorporam, de outro, uma reflexão com vista a melhorar o desempenho técnico e estrutural dos próprios produtos. Quando o design é aplicado às questões da moda sustentável, ambas as direções são percorridas. A evolução histórica e cultural de valores e dos significados, que levaram ao surgimento de uma nova estética combinada e sofisticada no setor da moda sustentável de luxo, foi reconstruída na Itália, por exemplo, por Danese (2011). A estudiosa reconhece uma linha de desenvolvimento que, dentro da valorização do usado, vai da estética da privação ao antagonismo social alcançando a ética do anticonsumismo.

A prática da reutilização (...) considerada sinal de privação e de pertencimento a grupos sociais que não têm muitas oportunidades para escolher o que vestir, em um alhures temporal e geográfico tornou-se marca de antagonismo e de rejeição do consumismo. (...) Sobretudo como consequência de comportamentos apresentados por subculturas juvenis, o reservatório inesgotável de roupas fora de uso serve para criar autonomamente novos estilos a baixo custo (DANESE, 2011, p. 49).

A tal evolução estética corresponde uma evolução ético-pragmática: comportamentos ditados principalmente pelas condições de necessidade são apoiados e substituídos por práticas que manifestam uma atitude de crítica social e política, e resultam num conjunto de escolhas expressivas, em que a dimensão estética é novamente dominante. Esta também é o motor que levou ao fenômeno vintage descrito como o fenômeno que permite

distinguir e classificar a qualidade dentro de uma enorme pilha de roupa usada. (...) A reutilização torna-se, assim, uma metáfora para o gesto de salvação de quem persiste no que foi abandonado, reconhecendo nele a beleza e restituindo-o a uma nova vida (DANESE, 2011, p. 49-50).

Nessa perspectiva, desenvolvem-se também os projetos de design, nos quais a fronteira entre a moda e a arte torna-se turva, em parte porque as pequenas tiragens das coleções de curto prazo incorporam mais os princípios da organização da produção artística que da industrial. Um bom exemplo dessa tendência é o designer Martin Margiela: "Quando pego um vestido que está lá, no chão no mercado de pulgas, na chuva, e o transformo, eu não chamo isso de destruição. É bonito usar aquilo que ninguém quer mais para fazer uma coisa atual" (citado por DANESE, 2011, p. 50). Na Itália, a designer Ilaria Venturini Fendi, fundadora da Carmina Campus, marco de pesquisa baseada na filosofia de reutilização de materiais, realiza uma experiência desse tipo, extraindo inspiração projetual para a suas séries limitadas de bolsas a partir do encontro com materiais destinados à eliminação, fruto de trabalhos em setores merceológicos diferentes da moda (resíduos da fabricação de móveis estofados, placas interruptoras de luz, mosquiteiros, automóveis etc.).

De um ponto de vista privilegiado, como o dos estudos de moda britânica, em 2008, Sandy Black havia identificado mais ou menos o mesmo processo, mostrando, porém, como na Grã-Bretanha era já então visível a tendência da moda convencional e de massa (marcas da High Street Fashion, bem como alguns dos principais varejistas britânicos) para absorver um interesse em coleções que promovessem as preferências estéticas da estação e contemporaneamente incorporassem princípios de sustentabilidade ambiental e social, devidamente comunicada aos consumidores. Nesse sentido, destacam-se experiências como as da H\&M, a varejista sueca que desenvolveu uma linha de produtos de algodão orgânico, apresentadas aos consumidores por meio de uma etiqueta de certificação, e os supermercados Coop, que criaram na Itália a marca Solidal, que comercializa roupas e acessórios de comércio equitativo e solidário.

Por sua parte, Sass Brown, designer e pesquisadora da moda britânica, coloca- 
-se em 2010 na mesma onda, explicitando dois elementos muito importantes para a compreensão da evolução contemporânea do fenômeno. 0 primeiro ponto levado em consideração por ela refere-se ao fato de que o design de moda sustentável, tendo processado a evolução estética anteriormente descrita, atingiu um nível de maturidade que o torna adequado aos segmentos considerados luxuosos da pirâmide do mercado de moda. Isso resultou em consequências na própria estrutura das coleções, que incorporam materiais e processos de produção ecológica e socialmente sustentáveis e, ao mesmo tempo, em uma atenção ao conteúdo estético que as torna compatíveis e competitivas com as coleções das mais inovadoras marcas de pesquisa, abandonando assim a estética excessivamente naturalista e anticonsumista que havia caracterizado as primeiras fases do fenômeno, e que ainda se encontra em alguns segmentos da moda sustentável (BROWN, 2010). 0 segundo elemento diz respeito à relação particular com o território desenvolvido pelas marcas que operam nesse setor. A pesquisadora destaca como os designers de moda ocidentais de todos os tempos foram muitas vezes inspirados por estéticas de países não ocidentais, com uma forte tradição artesanal que se exprime nos bordados, nas cores, nos tecidos, nas formas das roupas etc. Tradicionalmente, no entanto, tal inspiração era absorvida por designers ocidentais e não dava origem a qualquer parceria com designers e artesãos de países distantes. A partir de uma abordagem que visa a cooperação internacional, no âmbito da moda sustentável, foram desenvolvidos projetos em que a colaboração é explicitamente reconhecida e o resultado esteticamente refinado é o produto da interação entre as habilidades e conhecimentos amadurecidos em diferentes contextos sociais e geográficos. A colaboração pode ocorrer no plano do fornecimento de matérias-primas de grande qualidade, como é o caso da Zegna, uma histórica empresa têxtil italiana que, desde a década de 1920, investe numa rede global de criadores com os quais estabeleceu acordos comerciais e produtivos, estimulando o desenvolvimento da qualidade de sua lã. Ou pode envolver a realização de produtos artesanais semiacabados de conteúdo especializado, como as séries limitadas chamadas "made in", lançada pela Prada em 2010 para valorizar o artesanato local internacional. A colaboração também pode surgir diretamente da iniciativa da empresa de moda ou pode prever a participação em projetos de cooperação internacional, como no caso da Carmina Campus, que juntamente com a Agência ITC (International Trade Centre) das Nações Unidas, destinada a combater a pobreza na África, criando oportunidades de emprego, participa de uma série de projetos para a produção de têxteis semiacabados feitos por comunidades de mulheres microempreendedoras e que são posteriormente utilizados na produção realizada na Itália. 0 projeto Not charity, just work também se vale da contribuição de artesãos colaboradores da Carmina Campus que têm dado treinamento no local para aumentar o know-how das pessoas das comunidades e inclui uma capsule collection de bolsas produzidas inteiramente na África utilizando materiais reciclados no local.

0 aspecto importante dessas práticas é o encontro entre conhecimentos, cujas raízes se encontram em lugares e tradições diferentes, atualizando e ampliando a lógica da valorização das regiões, como já foi dito, constitui também o coração da economia manufatureira provincial italiana.

Quando o design se repropõe como uma ferramenta para abordar questões relacionadas à melhoria do desempenho dos produtos e à proteção do ambiente e relações sociais, ele se conjuga e se contamina com a pesquisa e a aplicação de inovações tecnológicas (FLETCHER, 2008). Nesse caso, como já foi referido anteriormente, 0 projeto pode se concentrar em diferentes etapas da cadeia de produção, desde a fase de cultivo e extração das fibras, por meio do ciclo de vida e modos de utilização do produto, até as estratégias para a eliminação final. Devido à grande complexidade dos processos envolvidos, revelou-se necessário desenvolver um conjunto de ferramentas que permitissem um monitoramento das diferentes medidas sustentáveis adotadas. Entre eles, a LCA (Life Cycle Assessment) que consiste em uma metodologia de análise que avalia o conjunto de interações de um produto com o meio ambiente, considerando todo seu ciclo de vida que inclui as fases de pré-produção (por exemplo, o cultivo, extração e produção de materiais), processamento, distribuição, uso (incluindo reutilização e manutenção), gestão até o final da vida. A LCA é reconhecida internacionalmente pelo ISO 14040 e 14044. 
Um principio fundamental sobre o qual os estudiosos e profissionais concordam é a necessidade de diferenciar os processos utilizados (BLACKBURN, 2009; DANGELICO; PONTRANDOLFO; PUJARI, 2013). 0 mercado mundial de têxteis, por exemplo, é ocupado em sua grande parte por um conjunto complexo de fibras químicas (man-made), das quais a melhor parte são fibras sintéticas derivadas do petróleo (em 2010, cerca de $62 \%$ do total), enquanto a categoria de biopolímeros (fibras artificiais obtidas a partir de celulose), sobre a qual se orienta a pesquisa sensivel à questão da sustentabilidade, constitui ainda um nicho restrito, pouco mais de $5 \%$ do total. Entre as fibras naturais, mais sustentáveis, de acordo com muitos, mas também de grande impacto sobre 0 meio ambiente (GALLO, 2008; VEZZOLI, 2004), o algodão é a mais prevalente (31\% do total, contra 1,5\% da lã). Essa concentração tem efeitos muito relevantes no plano ambiental; por isso, muitos projetos de criação de produtos, a alta performance de sustentabilidade estética e técnica estão intimamente ligados a programas de pesquisas tecnológicas que visam racionalizar o cultivo de fibras alternativas ao algodão convencional e a redução da dependência do sistema têxtil do petróleo e seus derivados. Esse tipo de projeto surge geralmente em contextos sociais e econômicos sensíveis para acolher tal variedade: em áreas climaticamente favoráveis à recuperação de determinadas culturas ou criações de rebanhos tradicionais, em regiões onde há um conhecimento difundido compatível com os novos padrões perseguidos, dentro de empresas industriais dedicadas a uma transformação de seus processos de produção em termos de sustentabilidade.

$\mathrm{Na}$ Itália, ao longo das últimas décadas, ganharam visibilidade alguns casos interessantes a esse respeito, enquanto muitas outras iniciativas estão em fase de experimentação e início, sinal da vitalidade de um processo que não pode mais ser certamente considerado uma moda passageira (DANSERO; CALDERA, 2012). A plataforma digital Sustainability-Lab ${ }^{2}$ reúne na Itália os operadores mais cuidadosos nesse setor, e os seus promotores firmaram parcerias estáveis com as principais feiras de têxtil-vestuário e moda para certificar os processos sustentáveis postos em prática por marcas e empresas interessadas também em comunicar à cadeia de suprimentos e aos consumidores finais seu compromisso nesse sentido. Um exemplo interessante desse compromisso foi a realização, para a Fiera Tessile Milano Unica (fevereiro de 2013), da primeira edição do guia dos "tecidos e acessórios sustentáveis", distribuído aos visitantes. Dez dos expositores da feira aceitaram se submeter a uma auditoria realizada pelos peritos da Sustainability-Lab para certificar o nivel de sustentabilidade de seus processos de produção.

Entre os projetos que são desenvolvidos nas diversas regiões da Itália, um caso interessante é o da província lanifícia de Biella, onde estão concentradas algumas das principais empresas têxteis que fabricam lã de alta qualidade. Os projetos desenvolvidos pela Câmara de Comércio e Indústria de Biella em parceria com a agência Lãs da Itália e Biella Woolcompany se propõem a viabilizar microcadeias de produção locais que realizem todas as fases do ciclo de produção de lã até a confecção de itens de vestuário, cobertores e outros produtos. Uma vez que a lã nativa não é adequada aos padrões de qualidade das empresas lanifícias de Biella, tais projetos visam um duplo propósito: de um lado, explorar novas possibilidades de usos da lã fora da cadeia de vestuário, de outro, melhorar a qualidade da lã por meio da seleção das espécies de reprodução e melhorias nas técnicas de tosa e de seleção pós-tosa (MAGNI, 2011, p. 60).

Em outras regiões, foram lançados projetos para o cultivo de fibras utilizadas em escalas definitivamente menores em relação à lã e ao algodão, mas ainda correspondentes à recuperação de culturas tradicionais. Esse é o caso, por exemplo, do cânhamo na região de Emília, do linho na planície de Lombardia e em Piemonte, da urtiga na Toscana e da piaçava em algumas regiões do sul como a Calábria (CELETTI, 2007). Nem sempre tais cultivos são destinados à fabricação de tecidos para a moda. Em vários casos, de fato, as fibras extraídas das plantações são de interesse para aplicações técnicas em diversas áreas completamente diferentes do setor vestuário.

Além disso, a produção de fibras man-made ostenta uma tradição significativa 
na Itália que remonta ao desenvolvimento da indústria química durante o período fascista (MERLO, 2003b; GAROFOLI; GIORDANI-ARAGNO, 1991; COLLI, 2003). Recentemente também têm sido desenvolvidos programas de pesquisa para a produção de fibras artificiais derivadas de matérias-primas naturais, em particular, do amido, celulose ou fontes de proteína e biodegradáveis. Atualmente, não há resultados significativos que apontem para uma aplicação imediata de biopolímeros na indústria têxtil, mas as experimentações estão ativas nesse campo. Um caso histórico, que ficou famoso pelo poeta futurista Filippo Tommaso Marinetti, em 1937, com 0 poema do vestido de leite, diz respeito à criação do lanital, uma fibra derivada da caseína do leite e produzida na década de 1930 pela SNIA. Recentemente, foi proposta uma fibra similar, produzida a partir de excedentes de produtos lácteos, o que representa uma experiência interessante embora a sua inclusão no mercado atual seja ainda marginal (MAGNI, 2011).

Em relação ao ciclo de vida do produto, uma questão muito interessante, mas ainda pouco explorada, refere-se aos modos de manutenção dos itens que tenham menor impacto ambiental. De acordo com alguns estudos, a manutenção de um artigo de poliéster durante o seu ciclo de vida normal consome seis vezes mais energia do que a necessária para produzi-lo (FLETCHER, 2008). Dispor de materiais que se sujem menos e que mantenham por mais tempo os padrões de higiene adequados às exigências dos consumidores, assim como os detergentes mais eficientes e compostos de substâncias químicas não prejudiciais, constitui um objetivo relevante do ponto de vista da proteção ambiental. Também o desenvolvimento de práticas colaborativas de manutenção, tais como as máquinas de lavar condominiais, difundidas já há algum tempo no norte da Europa, ou a mudança dos padrões culturais (diferentes em diversos países do mundo) sobre o sentido e o valor da limpeza são contribuições importantes no desenvolvimento da sustentabilidade ligada à indústria têxtil-vestuária e da moda. Conhecimentos, experiências, padrões culturais relacionados a contextos sociais e históricos específicos representam, assim, um recurso valioso na elaboração de estratégias de sustentabilidade ambiental e social nesses setores.

Sobre esse aspecto, na Itália não há ainda projetos particularmente significativos, até porque as condições históricas e sociais não são favoráveis a esse tipo de iniciativa. A relativa estabilidade das situações habitacionais da maior parte das familias italianas, residentes em casas próprias e com mobilidade geográfica limitada, que é complementada pela presença de uma indústria de eletrodomésticos que floresceu até tempos muito recentes, além dos estilos de vida com uma clara segmentação de gênero nas tarefas de cuidado e uma baixa participação das mulheres no trabalho remunerado, têm favorecido a privatização das práticas de limpeza doméstica (ASQUER, 2007). A isso se acrescenta uma ênfase no valor de higiene e limpeza como um sinal de modernidade e cuidado, legado pela recente modernização industrial (MORA, 2009a). A superação da lógica da posse pessoal e privada está se tornando visível também na Itália, mesmo em um segmento aparentemente muito tradicional do mercado de vestuário, o do aluguel. Até poucos anos atrás, esses serviços eram focados principalmente no vestuário de cerimônia e nas fantasias de carnaval/teatro. Recentemente, desenvolveram-se agências que colocam à disposição - de pessoas que por motivos profissionais precisam de uma roupa sempre cuidada e renovada - acesso a guarda-roupas inteiro das marcas de moda mais importantes, com fornecimento e manutenção semanal. Se esse serviço atende a uma necessidade individual dos clientes, constitui também uma medida eficaz de limitação de desperdícios e de racionalização do mercado, até mesmo na moda, que começou a se concentrar mais na produção de serviços que de mercadorias.

Ainda no âmbito do ciclo de vida dos produtos, as estratégias talvez mais populares, que envolvem em primeiro lugar os consumidores finais, mas cada vez mais também as empresas, referem-se ao prolongamento da vida dos artigos, por meio de práticas de reutilização, escambo ou troca. Obviamente, tais práticas surgem em contextos locais em que as pessoas estão ligadas por relações de amizade ou associação por pertencimentos e interesses culturais comuns. As paróquias, clubes e as associações, os centros sociais, grupos informais de amigos são os reservatórios naturais nos quais as roupas e objetos pessoais são trocados ou vendidos. São decididamente muito mais numerosas que nas décadas passadas também as pequenas lojas que oferecem 
pequenos serviços de alfaiataria, como barras e alteração de medidas. Seguindo a linha da criatividade sustentável, surgem também projetos em que o designer exercita seu domínio no redesenho de artigos já em posse do cliente, aos quais é dada uma nova cara. Esse é, por exemplo, o caso do atelier Gentucca Bini, em Milão.

A internet deu um forte impulso a tais práticas, favorecendo a criação de plataformas em que é possivel realizar formas de troca assíncronas e sem a necessidade de proximidade geográfica, aumentando efetivamente as possibilidades concretas de dar uma nova vida a artigos de vestuário e acessórios, recolocados dentro dos guarda-roupas de novos proprietários. Na Itália, são exemplos as plataformas reoose.com, zerorelativo.it, e-barty.it.

Também em termos de readaptação de peças, a internet oferece oportunidades, ampliando as potencialidades do chamado "faça você mesmo" por meio de sites que ensinam as técnicas e truques para transformar roupas fora de moda, e onde é possivel compartilhar habilidades e os produtos autoproduzidos. Entre os exemplos mais conhecidos estão os sites specchioedintorni.it e appuntidimodaefaidate.blogspot.it.

A fim de promover uma atenção para a extensão do ciclo de vida dos produtos, contribuem também algumas empresas que lançaram iniciativas de angariação de peças em desuso trazidas pelos clientes às lojas em troca de descontos ou promoções na compra de mercadoria nova. Os artigos assim recolhidos são depois selecionados com base na possibilidade de reutilização, e encaminhados aos circuitos de solidariedade locais ou para processos industriais de transformação de resíduos têxteis. Entre as iniciativas nesse campo, podemos destacar alguns importantes operadores do varejo de massa, como H\&M e Tezenis. Se essas iniciativas têm a indubitável vantagem de ajudar a chamar a atenção para a questão do desperdício no campo do consumo de moda, não se pode negar, no entanto, um aspecto que muitas vezes é destacado, especialmente por quem relaciona ao tema da sustentabilidade ambiental e social instâncias de tipo ético e político como os estudiosos que se colocam na linha do decrescimento (LATOUCHE, 2009; LATOUCHE; HARPAGĖS, 2011; PALLANTE, 2008). Na verdade, parece até certo ponto contraditório que empresas, cujo objetivo é aumentar o volume de vendas, sensibilizem os consumidores a novas compras por meio de um convite para reduzir os desperdícios.

Entre o prolongamento do ciclo de vida dos produtos e a redução dos desperdícios na eliminação de resíduos, são importantes os projetos que são definidos como "do berço ao berço" e que incorporam estratégias não de reutilização, mas propriamente de reciclagem. Nesses casos, os projetos muitas vezes são destinados à reciclagem de materiais descartados, utilizados em outros setores para a produção de fios de poliéster. 0 caso mais conhecido é certamente representado pela reciclagem de garrafas PET de água mineral e refrigerante, das quais é possível obter um filamento contínuo adequado para ser usado na produção de tecidos, como os sintéticos usados na fabricação de vestuário, mas também em enchimentos, não tecidos e materiais compostos (LUNGHI; MONTAGNINI, 2007).

0 caso mais interessante na Itália é o do fio contínuo de poliéster de alta qualidade Newlife ${ }^{\circledR}$, fabricado pela Saluzzo Yarns do Sinterama Group e utilizado por Armani, em 2012, na confecção de um vestido usado por Livia Firth no Green Carpet Challenge, plataforma idealizada por essa garota-propaganda e empresária (também atuante como consultora nessa área para grandes marcas de luxo) para promover a moda sustentável no mundo do cinema (GREENITALY, 2012). Igualmente interessante nessa direção são os produtos da RadiciGroup, que aplicou a LCA para seus poliésteres, e da Aquafil, que produz fio de poliamida da reciclagem de redes de pesca (MAGNI, 2011).

No que diz respeito à fase de descarte, já estão disponíveis alguns programas testados, como aquele que foi desenvolvido em 2005 pela Patagonia (MAYNARD, 2004), conhecida marca norte-americana de sportswear. 0 programa é chamado Common Threads Recycling Program ${ }^{3}$ e prevê a reciclagem dos artigos Patagonia em tecido sintético, algodão orgânico e polipropileno e os sintéticos Polartec de outras mar- 
cas (LUNGHI; MONTAGNINI, 2007). Esse tipo de processo na Itália possui uma antiga tradição localizada em Prato, região de transformação de retalhos em lã regenerada. Como destaca Magni (2011, p. 65), "reciclar retalhos tem permitido às empresas de Prato (...) adquirir competência nas tecnologias de seleção de materiais, no tratamento de fibras não homogêneas, na utilização de materiais de acabamento para melhorar materiais inferiores regenerados". Fica, então, evidente como o compromisso em business voltados à sustentabilidade pode levar à inovação, novos negócios, crescimentos, que se alimentam de uma rede de conhecimentos e habilidades que formaram a espinha dorsal dos sistemas industriais tradicionais já especializados em específicos setores merceológicos.

Um último tipo de abordagem sustentável na produção de moda é o que pode ser classificado como "criatividade e inclusão social" (LUNGHI, 2012). Trata-se de um grande número de iniciativas que se baseiam na criatividade artesanal no têxtil-vestuário em projetos de inclusão social de pessoas em situação de privação. Já são numerosas, por exemplo, as oficinas de alfaiatarias ativas em algumas das prisões mais lotadas da Itália. Em maio de 2013, foi lançada a Sigillo, a primeira agência nacional de coordenação do empreendedorismo das mulheres presas. 0 objetivo da agência, a primeira do gênero na Itália e na Europa, é cuidar de estratégias de produto, comunicação e posicionamento no mercado da produção das mulheres detidas nas oficinas de alfaiataria dentro das prisões. As alfaiatarias que operam em tais projetos são atentas, sobretudo, às dimensões sociais da sustentabilidade, embora muitas vezes atuem em colaboração com marcas e empresas que operam no mercado mainstream e, igualmente, atentas às características ambientais de seus processos produtivos. Casos significativos são entre outros os da prisão de San Vittore em Milão, da casa circondariale de Borgo San Nicola, em Bari, da prisão de Trani, e da prisão de Turim.

Como é evidente, mesmo nesses últimos casos particulares, a relação com o território e com os destinos sociais e culturais sociais das cidades e das regiões continua a ser um fator decisivo para o desenvolvimento e inovação na Itália: trata-se de valorizar, para as mais diversas formas criativas, as ligações e as formas de solidariedade que a estrutura campalinística italiana produziu historicamente, e que ao longo do tempo se desgastaram, mas que hoje podem constituir novamente um patrimônio estratégico para enfrentar o futuro. 


\section{NOTAS}

${ }^{[1]}$ Tradução: Simone Bueno da Silva. Revisão: Rafael Giardini Lenzi. 0 conteúdo deste artigo, elaborado em uma versão diferente, foi publicado em Salvatti e Sciolla (2013).

${ }^{[2]}$ Disponivel em: <http://www.sustainability-lab.net>. Acesso em: 7 jun. 2013.

${ }^{[3]}$ Disponivel em: <www.patagonia.com/recycle>. Acesso em: 7 jun. 2013.

\section{REFERÊNCIAS}

ASOUER, E. La rivoluzione candida: storia sociale della lavatrice in Italia (1945-1970). Roma: Carocci, 2007.

BARTHES, R. II match Chanel-Courrèges. In: . Il senso della moda. Turim: Einaudi, 2006, p. 84-89.

BECATIINI, G. Dal distretto industriale allo sviluppo locale: svolgimento e difesa di un'idea. Turim: Bollati Boringhieri, 2000.

BENJAMIN, W. Parigi, capitale del XIX secolo: progetti appunti e materiali 1927-1940. Turim: Einaudi, 1986.

BLACK, S. Eco-chic: the fashion paradox. Londres: Black Dog Publishing, 2008.

BLACKBURN, R. S. Sustainable textiles: life cycle and environmental impact. Cambridge, Reino Unido: Woodhead, 2009.

BREWARD, C.; GILBERT, D. (Org.). Fashion's world cities. Oxford: Berg, 2006.

BROWN, S. Eco fashion. Londres: Laurence King Publishing, 2010.

BUCCI, A. La moda degli stilisti leader: dal cambiamento alla stabilità. In: CERIANI, G.; GRANDI, R. (Org.). Moda: regole e rappresentazioni: il cambiamento, il sistema, la comunicazione. Milão: FrancoAngeli, 1995, p. 222-228.

; CODELUPPI, V. FERRARESI, M. II made in Italy: natura, settori e problemi. Roma:

\section{Carocci, 2011}

CELETTI, D. Filati di canapa: recenti sviluppi di una tradizione antica. II caso stylfil spa. In: FONDAZIONE ASSI. Annali di storia dell'impresa. Veneza: Marsilio, 2007, v. 19, p. 229-292.

CERIANI, G. Moda e pregnanza: i travestimenti della Gestalt. In: CERIANI, G.; GRANDI, R. (Org.). Moda: regole e rappresentazioni: il cambiamento, il sistema, la comunicazione. Milão: FrancoAngeli, 1995, p. 231-243.

COLLI, A. Fibre chimiche. In: BELFANTI, C. M.; GIUSBERTI, F. (Org.). Storia d'Itália: annali 19: la moda. Turim: Giulio Einaudi, 2003, p. 483-522.

DANESE, E. La dimensione sostenibile del fashion design. In: RICCHETTI, M.; FRISA, M. L. (Org.). II bello e il buono: le ragioni della moda sostenibile. Veneza: Marsilio, 2011, p. 49-56.

DANGELICO, R. M.; PONTRANDOLFO, P.; PUJARI, D. Developing sustainable new products in the textile and upholstered furniture industries: role of external integrative capabilities. Journal of Product Innovation Management, v. 30, n. 4, p. 642-658, jul. 2013.

DANSERO, E.; CALDERA, G. Green economy e tessile: chi passa per la cruna dell'ago. I Rapporto Green Economy, Ires Piemonte, dez. 2012. Disponivel em: <http://www.ires.piemonte.it/green/08_ Tessile.pdf>. Acesso em: 7 jun. 2013.

DE MARLY, D. Worth: father of haute couture. Nova York: Holmes \& Meier, 1990.

FINTONI, S. Produrre e distribuire moda: sourcing e delocalizzazione in un contesto globale: dove, come, con chi. Milão: FrancoAngeli, 2008.

FLETCHER, K. Sustainable fashion and textiles. Londres: Earthscan, 2008.

GALLO, A. Cotone: geopolitica di una commodity agricola. Geotema, Bolonha, n. 35-36, 2008.

GAROFOLI, M.; GIORDANI-ARAGNO, B. Le fibre intelligenti: un secolo di storia e cinquant'anni di moda. Milão: Electa, 1991.

GIACCARDI, C. Immagini di identità. In: CANOVA, G. (Org.). Dreams: i sogni degli italiani in 50 anni di pubblicità televisiva. Milão: Bruno Mondadori, 2004, p. 81-95.

GFT. Appunti sull'evoluzione del gruppo Gft: un'analisi condotta sui fondi dell'archivio storico. Turim: GFT, 1986. 
GNOLI, S. Moda: dalla nascita della haute couture a oggi. Roma: Carocci, 2012.

GREENITALY. L'economia verde sfida la crisi. Rapporto 2012. Disponível em: <www.unioncamere. gov.it/download/1914.html>. Acesso em: 7 jun. 2013.

GUENZA, F. Business sostenibile: un dialogo sugli stakeholder con Edward Freeman. In: RICCHETTI, M.; FRISA, M. L. (Org.). Il bello e il buono: le ragioni della moda sostenibile. Veneza: Marsilio, 2011, p. 17-24.

HETHORN, J.; ULASEWICZ, C. Sustainable fashion: why now?: a conversation about issues, practices, and possibilities. Nova York: Fairchild, 2008.

JUCKER, L. Nel labirinto dei marchi e dei certificati. In: RICCHETTI, M.; FRISA, M. L. (Org.). II bello e il buono: le ragioni della moda sostenibile. Veneza: Marsilio, 2011, p. 147-160.

LATOUCHE, S. La scommessa della decrescita. Milão: Feltrinelli, 2009.

; HARPAGĖS, D. II tempo della decrescita: introduzione alla frugalità felice. Milão: Eleuthera, 2011.

LIPOVETSKY, G. L'impero dell'effimero: la moda nelle societa moderne. Milão. Garzanti, 1989.

LUNGHI, C. Creative evasion: manifatture di moda in carcere. Milão: FrancoAngeli, 2012.

; MONTAGNINI, E. La moda della responsabilità. Milão: FrancoAngeli, 2007.

MAGGIONI, M. A.; NOSVELLI, M. La cultura, tra formazione ed innovazione, nei sistemi locali. In: OSSERVATORIO IMPRESA E CULTURA (Org.). Cultura and competitività per un nuovo agire imprenditoriale. Catanzaro: Rubbettino, 2003, p. 307-347.

MAGNI, A. Trend di consumo e produzione eco sostenibile nel sistema tessile e della moda. Geotema, Bolonha, n. 35-36, p. 15-20, 2008.

Materiali, processi, innovazione: la sostenibilità nell'industria tessile. In: RICCHETTI, M.; FRISA, M. L. (Org.). II bello e il buono: le ragioni della moda sostenibile. Veneza: Marsilio, 2011, p. 57-74.

MALOSSI, G. (Org.). II motore della moda: spettacolo, identità, design, economia: come l'industria produce ricchezza attraverso la moda. Florença: The Monacelli Press, 1998.

(Org.). Volare: l'icona italiana nella cultura globale. Bergamo: Bolis, 1999.

MARACCHI, G. La moda, le culture e le filiere locali, per un nuovo modello econômico. In: RICCHETTI, M.; FRISA, M. L. (Org.). Il bello e il buono: le ragioni della moda sostenibile. Veneza: Marsilio, 2011, p.133-146.

MAYNARD, M. Dress and globalisation. Nova York: Manchester University Press, 2004.

MERLO, E. Le origini del sistema moda. In: BELFANTI, C. M.; GIUSBERTI, F. (Org.). Storia d'Itália: annali 19: la moda. Turim: Giulio Einaudi, 2003a, p. 667-697.

. Moda italiana: storia di un'industria dall'Ottocento a oggi. Veneza: Marsilio, $2003 b$.

MORA, E. Fare moda: esperienze di produzione e consumo. Milão: Bruno Mondadori, 2009a.

Ellis Wasson, aristocracy and the modern world. Sociologica, Bolonha, n. 2-3,

2009b. Disponivel em: <http://www.sociologica.mulino.it/journal/article/index/Article/ Journal:ARTICLE:352/Item/Journal:ARTICLE:352>. Acesso em: 7 jun. 2013.

What is special in the collections?: fashion brands and semiotic saturation. In: PEDRONI, M. (Org.). From production to consumption: the cultural industry of fashion. Oxford: Inter-Disciplinary Press, 2013, p. 89-103.

MORINI, E. La semplice meravigliosa moda italiana. AnniCinquanta: la nascita della creatività Italiana. Milão: ArtificioSkira, mar.-jul. 2005.

OSSERVATORIO NAZIONALE DISTRETTI ITALIANI. IV Rapporto. Disponível em: <http://www. osservatoriodistretti.org/sites/default/files/IV-rapporto-osservatorio-distretti.pdf>. Acesso em: 17 maio 2013.

PALLANTE, M. Un programma politico per la decrescita. Rimini: Edizioni per la Decrescita Felice, 2008.

PAMBIANCO, C.; TESTONI, L. I signori dello stile: rivoluzione e successo della moda italiana nel mondo. Milão: Sperling \& Kupfer, 2008. 
PARIS, I. Oggetti cuciti: I'abbigliamento pronto in Italia dal primo dopoguerra agli anni settanta. Milão: FrancoAngeli, 2006.

PERNA, T. Fair trade: la sfida etica al mercato mondiale. Turim: Bollati Boringhieri, 1998.

PORTER, M. E. Location, competition, and economic development: local clusters in a global economy. In: Economic development quesrterly, v. 14, n. 1, p. 15-34, fev. 2000.

RICCHETTI, M. La sostenibilità e il futuro dell'industria italiana della moda. In: ; FRISA, M. L. (Org.). Il bello e il buono: le ragioni della moda sostenibile. Veneza: Marsilio, 2011, p.121-132.

ROCAMORA, A. Fashioning the city: Paris, fashion and the media. Londres: I.B. Tauris, 2009.

ROSS, R. J. Slaves to fashion: poverty and abuse in the new sweatshops. Michigan: University of Michigan Press, 2004.

RUGGERONE, L. (Org.). Al di là della moda: oggetti, storie, significati. Milão: FrancoAngeli, 2001.

SALVATI, M.; SCIOLLA, L. (Org.). L'Italia e le sue regioni (1945-2011). Roma: Treccani, 2013, v. 1.

SANTAGATA, W. La fabbrica della cultura: ritrovare la creatività per aiutare lo sviluppo del paese. Bolonha: Il Mulino, 2007.

SEMPRINI, A. Marche e mondi possibili: un approccio semiotico al marketing della moda. Milão: FrancoAngeli, 1993.

SILVERSTEIN, M. J.; FISKE, N. Trading up: la rivoluzione del lusso accessibile. Milão: Etas, 2004.

SIMMEL, G. Le metropoli e la vita dello spirito. Roma: Armando, 1986

STEELE, V. Fashion, Italian style. New Haven, Connecticut: Yale University Press, 2003.

TATTARA, G.; CORÒ, G.; VOLPE, M. Andarsene per continuare a crescere: la delocalizzazione internazionale come strategia competitiva. Roma: Carocci, 2006.

VEZZOLI, C. Design e sostenibilità. In: BERTOLA, P.; MANZINI, E. (Org.). Design multiverso: appunt di fenomenologia del Design. Milão: Edizioni Poli.Design, 2004.

WELTERS, L. The fashion of sustainability. In: HETHORN, J.; ULASEWICZ, C. Sustainable fashion: why now?: a conversation about issues, practices, and possibilities. Nova York: Fairchild, 2008, p. 7-29. 